\title{
Modulation of microRNAs by ionizing radiation in human gastric cancer
}

\author{
JINPENG HE ${ }^{1,2^{*}}$, JUNRUI HUA ${ }^{1 *}$, NAN DING ${ }^{1}$, SHUAI XU $^{1,2}$, RUI SUN ${ }^{3}$, \\ GUANGMING ZHOU $^{1}$, XIAODONG XIE ${ }^{4}$ and JUFANG WANG ${ }^{1}$
}

\author{
${ }^{1}$ Department of Space Radiobiology, Key Laboratory of Heavy Ion Radiation Biology and Medicine, \\ Institute of Modern Physics, Chinese Academy of Sciences, Lanzhou 73000; ${ }^{2}$ University of Chinese Academy \\ of Sciences, Beijing 100049; ${ }^{3}$ Department of Oncology, The First People's Hospital of Lanzhou, \\ Lanzhou 730000; ${ }^{4}$ School of Basic Medical Sciences, Lanzhou University, Lanzhou 730000, P.R. China
}

Received April 8, 2014; Accepted May 13, 2014

DOI: $10.3892 /$ or.2014.3246

\begin{abstract}
Gastric cancer is one of the most common cancers in China. Although surgery is the primary therapeutic method, radiotherapy has become an integral part, particularly in the early and intermediate stages of gastric cancer. microRNAs (miRNAs) are involved in the regulation of diverse cellular processes in response to intrinsic and extrinsic stress. A change in miRNA expression profile has been identified in various types of tumor cells in response to radiation; however, there is no relevant information concerning gastric cancer. In the present study, we investigated the miRNA profiles of two clinical gastric cancer samples exposed to X-rays using miRNA microarray. We found that 16 miRNAs were downregulated and 2 miRNAs were upregulated significantly in both irradiated samples when compared with the unirradiated samples. Decreases in the levels of miR-300 and miR-642 expression were confirmed by qRT-PCR in more clinical samples and in cultured cell lines. We predicted the targets of the two miRNAs with TargetScan and classified all the candidate targets with Gene Ontology, which indicated that both miR-300 and miR-642 potentially regulate cellular radiation response by modulating apoptosis, cell cycle regulation and DNA damage and repair pathway-related genes. Cell cycle assay and immunofluorescence assay demonstrated that miR-300 regulates radiation-induced G2 cell cycle arrest and
\end{abstract}

Correspondence to: Dr Jufang Wang, Institute of Modern Physics, Chinese Academy of Sciences, 509 Nanchang Road, Lanzhou 73000, P.R. China

E-mail: jufangwang@impcas.ac.cn

Dr Xiaodong Xie, School of Basic Medical Sciences, Lanzhou University, 222 Tianshui Road, Lanzhou 73000, P.R. China

E-mail: xdxie@1zu.edu.cn

*Contributed equally

Key words: microRNA, ionizing radiation, gastric cancer, miR-300, miR-642
DNA damage repair. In conclusion, our findings indicate that ionizing radiation modulates the miRNA expression profile, and the changes in several specific miRNAs such as miR-300 have the potential to be used in the treatment, diagnosis and prognosis of gastric cancer.

\section{Introduction}

Gastric cancer is the fourth most common malignancy worldwide, with an estimated 738,000 deaths in 2008 (1). In China, gastric cancer is the most commonly diagnosed carcinoma and the leading cause of cancer-related mortality. Notably, Gansu Province is one of the high-risk areas, particularly in Wuwei City where the mortality rate is nearly 5 times as high as the average level (2). To date, surgical resection is the primary treatment for gastric cancer (3), but both local and distant recurrence are high due to delayed treatment because of diagnostic limitations in early non-invasive detection.

microRNAs (miRNAs) are an abundant class of non-coding RNAs, $19-25$ nucleotides in length. miRNAs regulate various processes involved in cell progression such as cellular division and differentiation (4), development (5), cell cycle regulation (6) and apoptosis (7) by binding to 3'-UTR of the target gene mRNA, either by inducing mRNA degradation or by inhibiting mRNA translation. It is widely recognized that miRNAs play important roles in tumorigenesis acting as potent oncogenes or tumor-suppressor genes $(8,9)$ and may be novel biomarkers for cancer diagnosis and prognosis (10). According to recent experimental evidence, miRNA expression is dysregulated in gastric cancer (11), and miRNA clusters such as miR-106b-25 (12) and miR-222-221 (13) take part in cellular growth or apoptosis. Thus, it is hopeful that miRNAs may become efficient targets for the diagnosis and prognosis of gastric cancer.

Radiotherapy, one widely used treatment for most malignant tumors, has become an integral part of gastric cancer treatment, particularly in the early and intermediate stages of gastric cancer (14-16). Cells present DNA damage, cell cycle arrest or apoptosis in response to ionizing radiation (IR) (17). Recently, it has been reported that radiation modulates the miRNA expression profile in human endothelial 
cells (18), prostate cancer $(19,20)$, brain cancer (21) and lung cancer $(21,22)$. Moreover, miRNAs play a critical role in multidrug resistance in human gastric cancer (23-25). However, no research concerning the change in expression profile in response to radiation and the roles of miRNAs in DNA damage responses have been reported in gastric cancer to date. In the present study, we aimed to identify the dysregulation of miRNAs responding to IR and their potential influences on cellular responses in gastric cancer.

\section{Materials and methods}

Cell culture. Human gastric cancer cell lines BGC823 and MGC803 were purchased from the Institutes of Biochemistry and Cell Biology, Chinese Academy of Sciences (Shanghai, China). Cells were maintained at $37^{\circ} \mathrm{C}$ in a $5 \% \mathrm{CO}_{2}$ atmosphere in RPMI-1640 medium (Gibco, Grand Island, NY, USA) with $10 \%$ fetal bovine serum (Hyclone, Logan, UT, USA) and $100 \mathrm{U} / \mathrm{ml}$ penicillin and $100 \mathrm{mg} / \mathrm{ml}$ streptomycin.

Clinical samples. Ten human gastric cancer tissue samples were obtained from the Department of Oncology, The First People's Hospital of Lanzhou City. The corresponding adjacent normal gastric tissues were also obtained. Human gastric cancer tissue samples from patients were obtained with informed consent under institutional review board approved protocols. Samples were immersed in RNAlater (Ambion, Foster City, CA, USA) $2 \mathrm{~h}$ after surgery and were then stored at $-20^{\circ} \mathrm{C}$.

Irradiation. Clinical tissue samples were irradiated immediately after surgical resection at Lanzhou General Hospital, Lanzhou Command with 4 Gy of X-rays (6 MV, $0.8 \mathrm{~Gy} / \mathrm{min})$. Cells were irradiated with a laboratory X-ray source (RX-650; Faxitron Bioptics, USA) at a dose rate of $0.8 \mathrm{~Gy} / \mathrm{min}(100 \mathrm{keV}$, $5 \mathrm{~mA}$ ). Cells and tissue samples were split with TRIzol reagent (Invitrogen, Eugene, OR, USA) $2 \mathrm{~h}$ after irradiation.

RNA preparation. Total RNAs of cells and tissue samples were extracted using TRIzol reagent according to the manufacturer's instructions. The quality and quantity of total RNAs were tested by BioPhotometer Plus (Eppendorf, Hamburg, Germany) and denaturing agarose gel electrophoresis.

microRNA microarray analysis. Two different clinical tissue samples were used for microarray analysis. Total RNAs were isolated with TRIzol reagent $2 \mathrm{~h}$ after irradiation. Then the miRNAs were labeled with Hy3 using the miRCURY ${ }^{\mathrm{TM}}$ Array Power Labeling kit (Exiqon, Vedbaek, Denmark) and hybridized respectively on a miRCURY ${ }^{\mathrm{TM}}$ LNA microRNA array (version 10.0, Exiqon) as previously described (26). Microarray images were obtained by using a Genepix 4000B scanner (Axon Instruments, Union City, CA, USA) and processed and analyzed with Genepix Pro 6.0 (Axon Instruments) and Microsoft Excel software (Microsoft Campus, Redmond, WA, USA).

Quantitative RT-PCR for miRNA. Total RNA was extracted using TRIzol reagent according to the manufacturer's protocol. Reverse transcription was performed using the All-in-One ${ }^{\mathrm{TM}}$ First-Strand cDNA Synthesis kit (GeneCopoeia,
Guangzhou, China). To quantify hsa-miR-300 and hsa-miR-642 expression, real-time PCR was performed using All-in-One ${ }^{\mathrm{TM}}$ miRNA qPCR Detection kit (GeneCopoeia) based on SYBR-Green according to the manufacturer's protocol. U6 snRNA was used to normalize the relative amount of miRNA. The fold-change of miRNA was calculated using the $2^{-\Delta \Delta C_{\mathrm{T}}}$ method (27).

miRNA target prediction and gene ontology. Target prediction of candidate miRNAs was carried out with TargetScanHuman (release 5.1) (http://www.targetscan.org/). The functions of the miRNA target genes were analyzed on the Gene Ontology website (http://www.geneontology.org/).

Cell cycle assay. MGC803 or BGC823 cells $\left(1.5 \times 10^{5}\right)$ were seeded into 12-well plates. Transfection of miRNA duplexes (Ambion) including miR-300 precusor (pre-miR-300) and negative control (pre-neg) was performed $24 \mathrm{~h}$ later using Lipofectamine 2000 (Invitrogen). Cells were exposed to $1 \mathrm{~Gy}$ of X-rays after $5 \mathrm{~h}$ and the medium was then replaced with fresh culture medium. Cells were fixed at $-20^{\circ} \mathrm{C}$ and then stained with $50 \mu \mathrm{g} / \mathrm{ml}$ propidium iodide $16 \mathrm{~h}$ after irradiation. A FACSCalibur flow cytometer (Becton Dickinson, Franklin Lakes, NJ, USA) and FlowJo software (version 6.0, Tree Star, Ashland, OR, USA) were used to analyze the cell cycle for each sample.

Immunofluorescence. Immunofluorescence assay was conducted according to a previous report (28). In brief, cells were fixed in $4 \%$ paraformaldehyde for $10 \mathrm{~min}$ and in methanol at $-20^{\circ} \mathrm{C}$ for $20 \mathrm{~min}$, permeabilized with $0.5 \%$ Triton $\mathrm{X}-100$ for $10 \mathrm{~min}$, blocked with 5\% skim milk for $2 \mathrm{~h}$ and stained with the primary antibody [rabbit anti-53BP1 antibody purchased from Santa Cruz Biotechnology (Santa Cruz, CA, USA) for $2 \mathrm{~h}$. The bound antibody was visualized using Alexa Fluor $^{\circledR} 594$ anti-rabbit antibody (Molecular Probes, Eugene, OR, USA), and cell nuclei were counterstained with DAPI solution (Invitrogen). Images were captured with a laser confocal microscope (Carl Zeiss LSM 700; Jena, Germany). 53BP1 foci were counted using a fluorescence microscope (Leica DMI6000B; Wetzlar, Germany), and a minimum of 100 cells were scored for each sample.

Statistical analysis. Results are expressed as means \pm SD. The statistical significance of the results was determined by Student's t-tests using Microsoft Excel software (Microsoft Campus).

\section{Results}

Alteration of the miRNA profile in gastric cancer exposed to $I R$. To identify the miRNA expression changed by ionizing radiation, we exposed two independent clinical gastric cancer tissues to $4 \mathrm{~Gy}$ of X-rays. The miRNA profiles of unirradiated and irradiated samples were obtained by miRNA microarray. The Venn diagram presenting the number of downregulated and upregulated miRNAs after 4 Gy of X-ray exposure is shown in Fig. 1A. In both irradiated samples, we identified that expression levels of 18 miRNAs were altered $>1.5$-fold, among which 16 miRNAs were downregulated and 
A

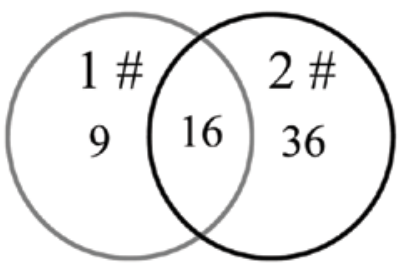

Downregulated miRNAs

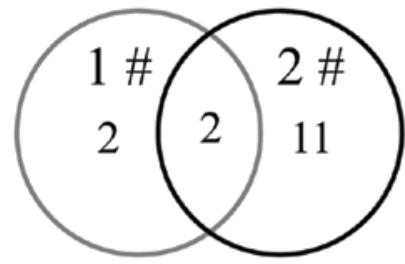

Upregulated miRNAs
B

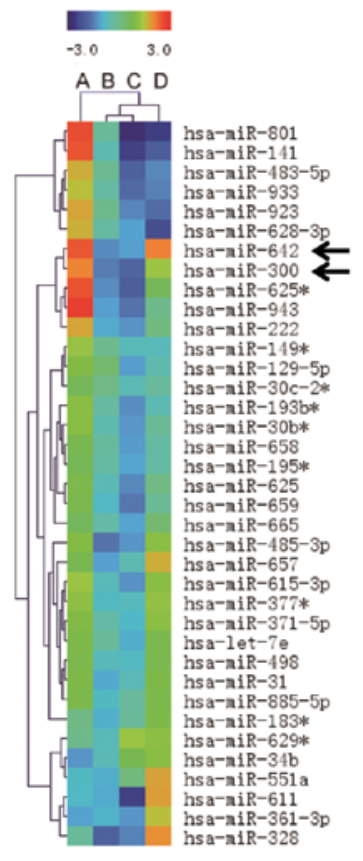

C
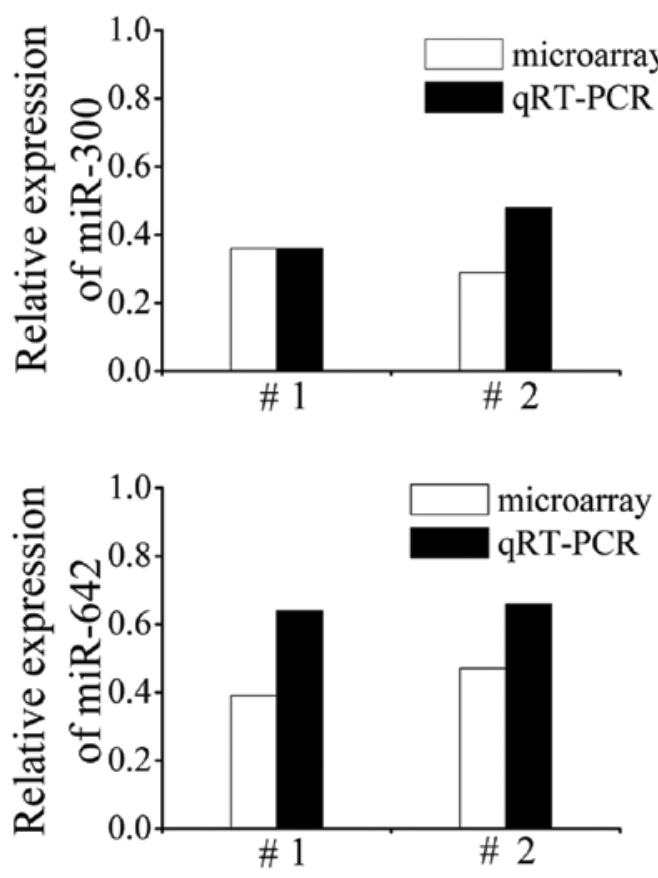

Figure 1. Alteration of the miRNA profile in gastric cancer exposed to IR. (A) Based on the miRNA microarray data, the Venn diagram presents the number of downregulated or upregulated miRNAs after exposed to $4 \mathrm{~Gy}$ of X-rays in both clinical samples. (B) Hierarchical clustering of miRNA expression obtained with Exiqon miRNA microarray (version 10.0) in unirradiated or irradiated clinical samples. Bars represent the differential levels of miRNA expression. The arrows indicate hsa-miR-300 and hsa-miR-642 whose expression levels were upregulated in gastric cancer while downregulated after exposed to 4 Gy of X-rays. A, clinical cancer sample 1 (0 Gy); B, clinical cancer sample 1 (4 Gy); C, clinical cancer sample 2 (4 Gy); D, clinical cancer sample 2 (0 Gy). (C) The expression levels of miR-300 and miR-642 were confirmed by qRT-PCR in the same irradiated samples. The expression levels were normalized with the matched 0 Gy cancer samples. \#1, clinical cancer tissue sample 1 (4 Gy vs. 0 Gy); \#2, clinical cancer tissue sample 2 (4 Gy vs. 0 Gy).

2 miRNAs were upregulated. These miRNAs and the fold change are shown in Table I. Notably, hierarchical clustering results showed that miR-300 and miR-642 expression levels were upregulated in gastric cancer while IR reduced their expression levels (Fig. 1B). Next, we validated the decreased expression of miR-300 and miR-642 which were downregulated $>2$-fold in the miRNA microarray results using quantitative RT-PCR (qRT-PCR) in the two gastric cancer samples exposed to X-rays (Fig. 1C).

Verification of the downregulation and putative target prediction of miR-300 and miR-642. Since miR-300 and miR-642 expression levels were decreased in the two gastric cancer samples, we verified their downregulation using additionalclinical gastric cancer tissues $(\mathrm{n}=10)$ and two cultured gastric cancer cell lines (BGC823 and MGC803) exposed to 4 Gy of $\mathrm{X}$-rays by qRT-PCR method. The results showed that miR-300 was significantly downregulated in 8 of the 10 clinical gastric cancer tissues and in both cell lines while miR-642 was downregulated in 9 of the 10 clinical gastric cancer tissues and in both cell lines (Fig. 2A and B), implying the general downregulation of miR-300 and miR-642 in gastric cancer after irradiation.

We employed TargetScanHuman (release 5.1) to predict the potential target genes of miR-300 and miR- 642 . Hundreds of candidate targets were obtained for each miRNA through the 2-8 nucleotides as seed sequence. Then, we classified all the candidate targets with Gene Ontology (GO). Based on the cellular response to ionizing radiation damage (17), the targets related to apoptosis (GO: 0006915), cell cycle regulation (GO: 0000074) or DNA damage and repair (GO: 0006281) are summarized in Table II. The results suggest that both miR-300 and miR-642 may play important roles in cellular radiation response by modulating related pathways.

miR-300 rescues IR-induced $G 2$ cell cycle arrest and promotes $D N A$ damage repair. To validate the target prediction that 
A

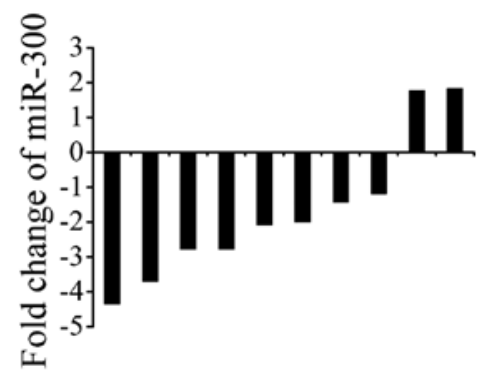

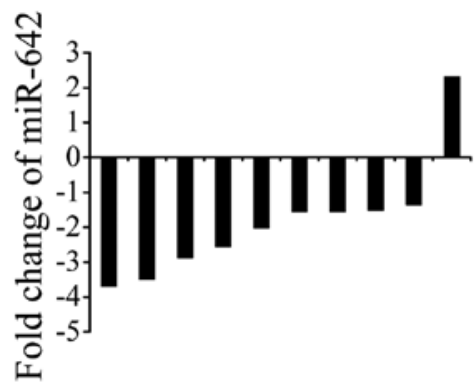

B
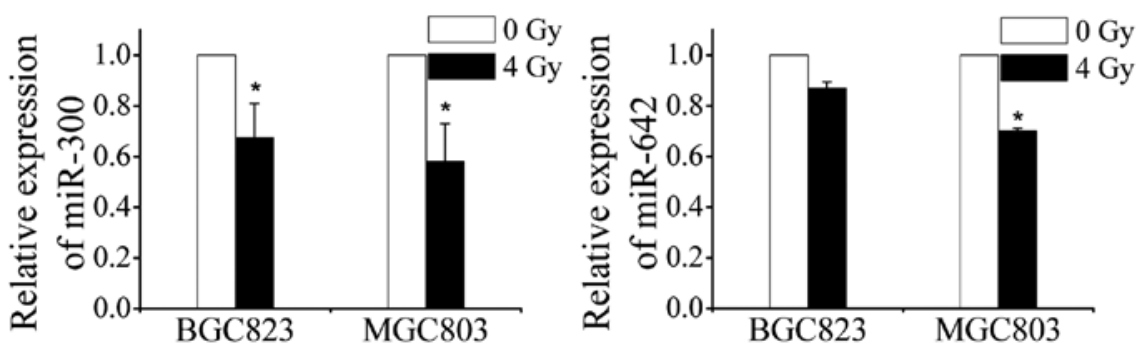

Figure 2. IR suppresses miR-300 and miR-642 expression levels in gastric cancer. qRT-PCR method was employed to test the expression levels of miR-300 and miR-642. (A) Fold change of the miR-300 and miR-642 expression levels in clinical gastric cancer tissues $2 \mathrm{~h}$ after $4 \mathrm{~Gy}$ of X-ray irradiation. (B) Relative changes in the miR-300 and miR-642 expression levels in gastric cancer cell lines (BGC823 and MGC803) 2 h after 4 Gy of X-ray irradiation. Data with error bars represent the means of at least three independent experiments. Error bars, \pm SD. A two tailed Student's t-test was used to determine the P-values. * $\mathrm{P}<0.05$.

Table I. Levels of miRNA altered more than 1.5-fold following irradiation in two clinical samples.

\begin{tabular}{lrr}
\hline & \multicolumn{2}{c}{ Fold change $^{\mathrm{a}}$} \\
\cline { 2 - 3 } miRNA & $\# 1^{\mathrm{b}}$ & $\# 2^{\mathrm{c}}$ \\
\hline hsa-let-7a & -2.00 & -1.85 \\
hsa-miR-138-1* & 1.58 & 5.17 \\
hsa-miR-141 & -1.52 & -5.26 \\
hsa-miR-24-1* & -1.85 & -2.94 \\
hsa-miR-300 & -2.78 & -3.45 \\
hsa-miR-377* & -1.75 & -1.67 \\
hsa-miR-423-3p & -1.54 & -2.00 \\
hsa-miR-485-3P & -3.03 & -2.33 \\
hsa-miR-490-5p & -1.92 & -1.72 \\
hsa-miR-498 & -1.61 & -1.72 \\
hsa-miR-615-3p & -1.61 & -2.38 \\
hsa-miR-625 & -1.54 & -2.56 \\
hsa-miR-625* & -2.50 & -3.85 \\
hsa-miR-637 & 1.80 & 2.32 \\
hsa-miR-642 & -2.56 & -2.13 \\
hsa-miR-657 & -2.17 & -1.52 \\
hsa-miR-659 & -1.79 & -2.94 \\
hsa-miR-943 & -2.17 & -3.03 \\
\hline
\end{tabular}

${ }^{\mathrm{a} A}$ minus sign (-) in front of the number indicates a downregulated value. ${ }^{\mathrm{b}}$ Clinical cancer tissue sample 1 (4 Gy vs. $0 \mathrm{~Gy}$ ). ${ }^{\mathrm{c}} \mathrm{Clinical}$ cancer tissue sample 2 (4 Gy vs. 0 Gy).

miR-300 and miR-642 may be involved in cell cycle regulation and DNA damage repair, we tested the cell cycle and the
Table II. Predicted targets of miR-300 and miR-642.

\begin{tabular}{|c|c|c|c|}
\hline \multirow[b]{2}{*}{ miRNA } & \multicolumn{3}{|c|}{ Function of the target genes } \\
\hline & $\begin{array}{c}\text { Apoptosis } \\
\text { (GO: 0006915) }\end{array}$ & $\begin{array}{c}\text { Cell cycle } \\
\text { (GO: } 0000074)\end{array}$ & $\begin{array}{l}\text { DNA damage } \\
\text { repair } \\
(\mathrm{GO}: 0006281)\end{array}$ \\
\hline \multirow[t]{5}{*}{$\operatorname{miR}-300$} & BCL2L11 & CCNK & ATAD5 \\
\hline & GAS2 & KLF4 & TP53BP1 \\
\hline & CASP8AP2 & NASP & \\
\hline & APAF1 & TP53 & \\
\hline & DLC1 & & \\
\hline \multirow[t]{6}{*}{ miR-642 } & TP53 & CDK10 & XPA \\
\hline & CASPS2 & CHFR & MRE11A \\
\hline & CASPS7 & ING4 & PRELD1 \\
\hline & CASPS9 & GRB2 & \\
\hline & CASPS 10 & & \\
\hline & BCL2L11 & & \\
\hline
\end{tabular}

53BP1 focus kinetics in MGC803 and BGC823 cells exposed to X-rays.

Results of the flow cytometry showed that $1 \mathrm{~Gy}$ of $\mathrm{X}$-rays induced marked G2 cell cycle blockage, while cells in the G2 phase were decreased from $43.33 \pm 2.45$ to $21.48 \pm 2.17 \%(\mathrm{p}=0.039)$ in the MGC803 cells transfected with pre-miR-300 (Fig. 3A). In addition, the effects were more evident in the BGC 823 cells $(\mathrm{p}=0.0027)$; miR-300 overexpression released $\mathrm{G} 2$ cell arrest induced by $1 \mathrm{~Gy}$ of $\mathrm{X}$-rays nearly to the unirradiated level (Fig. 3B). These results 
A
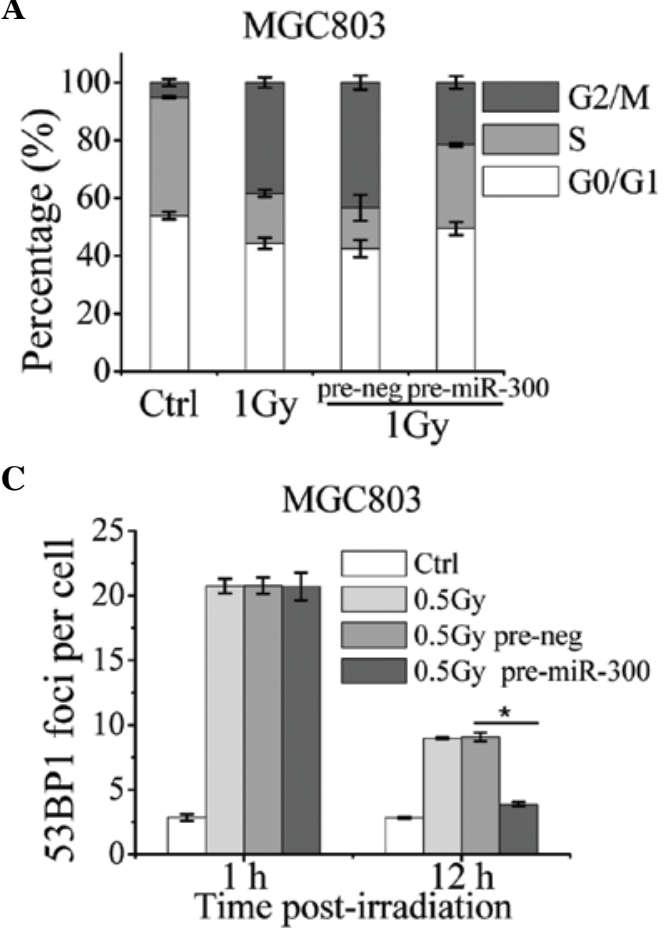

E

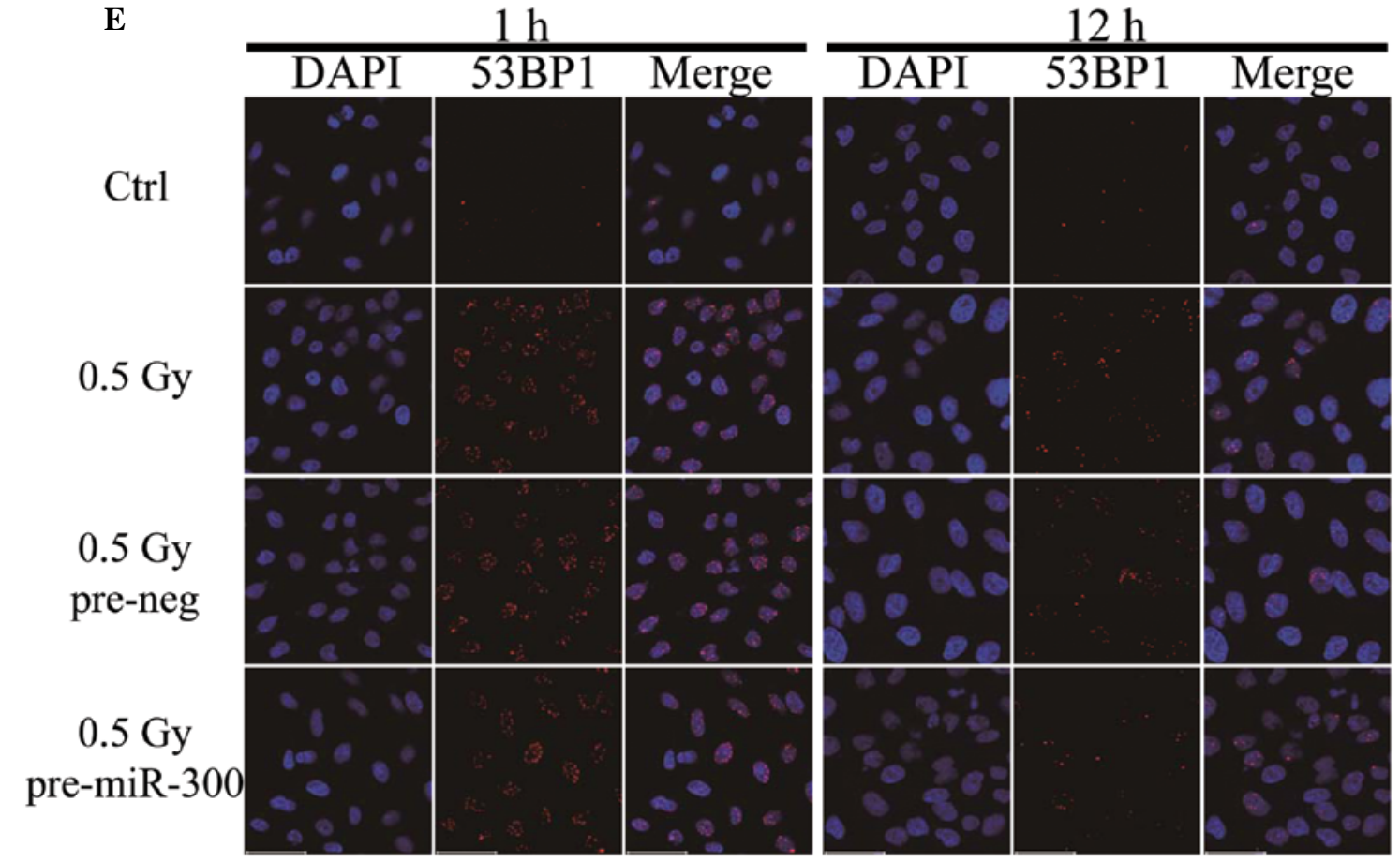

B

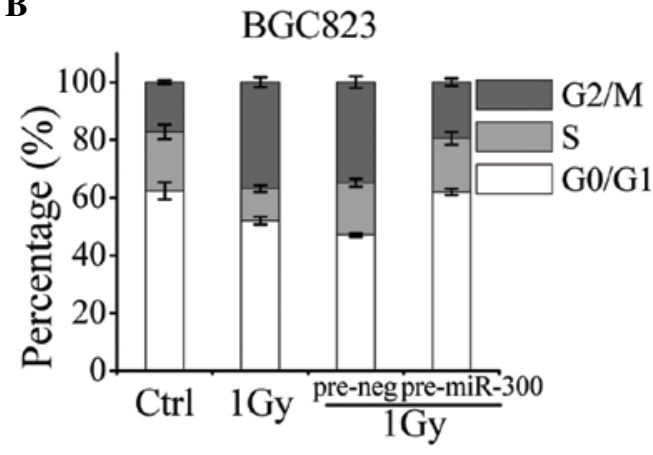

D

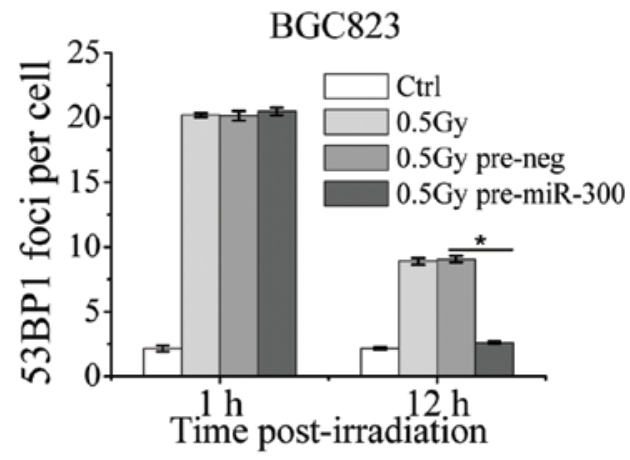

$12 \mathrm{~h}$

Figure 3. miR-300 regulates IR-induced G2 cell cycle arrest and DNA damage repair. Cell cycle distribution was analyzed in (A) MGC803 and (B) BGC823 cells without or with transfection of pre-neg or pre-miR-300 by flow cytometry $16 \mathrm{~h}$ after irradiation. $53 \mathrm{BP} 1$ foci were assessed in (C) MGC803 and (D) BGC823 cells without or with transfection of pre-neg or pre-miR-300 $1 \mathrm{~h}$ or $12 \mathrm{~h}$ post-irradiation. Error bars, \pm SD. A two tailed Student's t-test was used to determine the P-values. ${ }^{*} \mathrm{P}<0.05$. (E) Images of 53BP1 foci by confocal microscopy in MGC 803 cells; scale bar, $50 \mu \mathrm{m}$. Data with error bars represent the means of at least three independent experiments. Ctrl, cells without any treatment.

indicate that IR-induced miR-300 suppression impairs the cellular cell cycle recover.

The formation of 53BP1 foci is widely used as a marker of DNA double-strand breaks induced by ionizing radiation. To investigate the effect of miR-300 on DNA damage and repair ability, we tested 53BP1 focus kinetics in MGC803 and BGC823 cells transfected with pre-miR-300 or pre-neg. The measurement of 53BP1 foci at $1 \mathrm{~h}$ and $12 \mathrm{~h}$ post-irradiation with $0.5 \mathrm{~Gy}$ of X-rays showed that no difference was observed $1 \mathrm{~h}$ after irradiation between the two groups. However, $12 \mathrm{~h}$ after irradiation the number of 53BP1 foci in the group transfected with pre-miR-300 was significantly less than that in the MGC803 cells transfected with pre-neg (Fig. 3C and E). BGC823 cells demonstrated similar results (Fig. 3D). These 
data imply that miR-300 does not influence the cellular response to DNA damage but elevates the cellular DNA damage repair ability.

\section{Discussion}

Radiotherapy is widely used for the treatment of cancer. Since miRNAs are often located in fragile sites of the genome (29), it has been suggested that IR can trigger or disrupt the expression of these fragile sites consequently resulting in a dysregulated miRNA profile. To date, there are vast amounts of data concerning miRNA alterations and their functions in response to ionizing radiation in human normal or tumor cells (30-34); however, few data are available in regards to gastric cancer. Moreover, further investigation must be carried out to clarify whether IR or chemo-induced miRNA alterations in tumor cells are a product of disruption in epigenetics or an initiating mutational event.

In the present study, we tested the miRNA profile of clinical gastric cancer tissues irradiated with $\mathrm{X}$-rays and found that 18 miRNAs were markedly dysregulated in gastric cancer in response to IR, among which 16 miRNAs were significantly downregulated and 2 miRNAs were upregulated. The changes of miRNA expression profile may provide a new method for the diagnosis and prognosis of gastric cancer.

An miRNA can modulate the cellular response to IR-induced DNA damage through inhibition of its target genes. Lal et al showed that overexpression of miR-24 enhanced radiosensitivity by targeting $\mathrm{H} 2 \mathrm{AX}(35)$. miR-421 (36) and miR-101 (37) were found to efficiently target ATM and sensitize tumor cells to IR. Wang et al found that IR downregulated miR-185 expression, while elevation of miR-185 sensitized renal carcinoma cells to IR and enhanced radiation-induced apoptosis and proliferation inhibition by repressing ATR (38). miR-182 directly downregulates BRCA1 expression and impairs homologous recombination-mediated repair and renders cells hypersensitive to IR (39). On the other hand, DNA damage response factors, ATM (40) and BRCA1 (41) can regulate miRNA biogenesis via KSRP or DROSHA microprocessor complex, which are key players of miRNA biogenesis, suggesting that miRNA expression may be regulated by IR indirectly. In gastric cancer, it has been reported that inhibition of miR-221/222 enhanced radiosensitivity by targeting PTEN (42). We further identified that miR-300, one of the downregulated miRNAs post irradiation, can affect the cellular responses to radiation by relieving IR-induced G2 cell cycle arrest and promoting the cellular DNA damage repair ability.

The abundance of miR-300 and miR-642 is not high in various human tissues and cell lines $(43,44)$ so that little has been reported concerning their expression patterns and functions until recently. Recently, studies indicate that miR-300 and miR-642 are involved in the cisplatin-based chemo-response in cancer cells. Kumar et al identified that miR-300 and miR-642 were upregulated in a human cisplatin-resistant ovarian cancer cell line and that miR-300 may be an important regulator for ovarian cancer chemotherapy by targeting TGF- $\beta$ and apoptotic pathways (45). In addition, Nordentoft et al found that downregulation of miR-642 increased cisplatin sensitivity in human bladder cancer cell lines (46). Our data demonstrated that expression of miR-300 and miR-642 was upregulated in gastric cancer compared with normal gastric tissues and both miRNAs were downregulated after exposure to X-rays. Although increased expression of miR-300 and miR-642 in gastric cancer suggests their oncogenicity and decreased expression in response to chemotherapy or radiation exposure provides evidence for cancer therapy, the direct target genes and regulation pathways of miR-300 and miR-642 need to be further investigated. In conclusion, our study provides evidence that miRNAs are involved in the regulation of radiation responses in gastric cancer and changes in expression of specific miRNAs such as miR-300 have the potential to be used in the treatment, diagnosis and prognosis of gastric cancer.

\section{Acknowledgements}

The authors are grateful to Dr Sha Li of the Lanzhou General Hospital, Lanzhou Command, Lanzhou, China, for her assistance with clinical sample radiation; Hailong Pei, Qingxiang Gao and Liang Peng for assistance with flow cytometry; and Xurui Zhang for assistance with confocal microscopy. This study was supported by grants from the National Natural Science Foundation of China (nos. 31270895, 81272454 and U1232125).

\section{References}

1. Jemal A, Bray F, Center MM, Ferlay J, Ward E and Forman D: Global cancer statistics. CA Cancer J Clin 61: 69-90, 2011.

2. Yang L: Incidence and mortality of gastric cancer in China. World J Gastroenterol 12: 17-20, 2006.

3. Zhu X and Li J: Gastric carcinoma in China: current status and future perspectives (Review). Oncol Lett 1: 407-412, 2010.

4. Miska EA: How microRNAs control cell division, differentiation and death. Curr Opin Genet Dev 15: 563-568, 2005.

5. Alvarez-Garcia I and Miska EA: MicroRNA functions in animal development and human disease. Development 132: 4653-4662, 2005.

6. Bueno MJ and Malumbres M: MicroRNAs and the cell cycle. Biochim Biophys Acta 1812: 592-601, 2011.

7. Jovanovic $M$ and Hengartner MO: miRNAs and apoptosis: RNAs to die for. Oncogene 25: 6176-6187, 2006.

8. Esquela-Kerscher A and Slack FJ: Oncomirs - microRNAs with a role in cancer. Nat Rev Cancer 6: 259-269, 2006.

9. Ryan BM, Robles AI and Harris CC: Genetic variation in microRNA networks: the implications for cancer research. Nat Rev Cancer 10: 389-402, 2010.

10. Yanaihara N, Caplen N, Bowman E, et al: Unique microRNA molecular profiles in lung cancer diagnosis and prognosis. Cancer Cell 9: 189-198, 2006.

11. Wu WK, Lee CW, Cho $\mathrm{CH}$, et al: MicroRNA dysregulation in gastric cancer: a new player enters the game. Oncogene 29: 5761-5771, 2010.

12. Petrocca F, Visone R, Onelli MR, et al: E2F1-regulated microRNAs impair TGF $\beta$-dependent cell-cycle arrest and apoptosis in gastric cancer. Cancer Cell 13: 272-286, 2008.

13. Kim YK, Yu J, Han TS, et al: Functional links between clustered microRNAs: suppression of cell-cycle inhibitors by microRNA clusters in gastric cancer. Nucleic Acids Res 37: 1672-1681, 2009.

14. Hazard L, O'Connor J and Scaife C: Role of radiation therapy in gastric adenocarcinoma. World J Gastroenterol 12: 1511-1520, 2006.

15. McCloskey SA and Yang GY: Benefits and challenges of radiation therapy in gastric cancer: techniques for improving outcomes. Gastrointest Cancer Res 3: 15-19, 2009.

16. Buergy D, Lohr F, Baack T, et al: Radiotherapy for tumors of the stomach and gastroesophageal junction - a review of its role in multimodal therapy. Radiat Oncol 7: 192, 2012.

17. Li L, Story M and Legerski RJ: Cellular responses to ionizing radiation damage. Int J Radiat Oncol Biol Phys 49: 1157-1162, 2001. 
18. Wagner-Ecker M, Schwager C, Wirkner U, Abdollahi A and Huber PE: MicroRNA expression after ionizing radiation in human endothelial cells. Radiat Oncol 5: 25, 2010.

19. Josson S, Sung SY, Lao K, Chung LW and Johnstone PA Radiation modulation of microRNA in prostate cancer cell lines. Prostate 68: 1599-1606, 2008.

20. O'Kelly F, Marignol L, Meunier A, Lynch TH, Perry AS and Hollywood D: MicroRNAs as putative mediators of treatment response in prostate cancer. Nat Rev Urol 9: 397-407, 2012.

21. Niemoeller OM, Niyazi M, Corradini S, et al: MicroRNA expression profiles in human cancer cells after ionizing radiation. Radiat Oncol 6: 29, 2011.

22. Shin S, Cha HJ, Lee EM, et al: Alteration of miRNA profiles by ionizing radiation in A549 human non-small cell lung cancer cells. Int J Oncol 35: 81-86, 2009.

23. Xia L, Zhang D, Du R, et al: miR-15b and miR-16 modulate multidrug resistance by targeting BCL2 in human gastric cancer cells. Int J Cancer 123: 372-379, 2008

24. Zhu W, Xu H, Zhu D, et al: miR-200bc/429 cluster modulates multidrug resistance of human cancer cell lines by targeting BCL2 and XIAP. Cancer Chemother Pharmacol 69: 723-731, 2012

25. Wang F, Li T, Zhang B, et al: MicroRNA-19a/b regulates multidrug resistance in human gastric cancer cells by targeting PTEN. Biochem Biophys Res Commun 434: 688-694, 2013.

26. Castoldi M, Schmidt S, Benes V, et al: A sensitive array for microRNA expression profiling (miChip) based on locked nucleic acids (LNA). RNA 12: 913-920, 2006.

27. Livak KJ and Schmittgen TD: Analysis of relative gene expression data using real-time quantitative PCR and the $2-{ }^{-\Delta \Delta C_{(T)}}$ method. Methods 25: 402-408, 2001.

28. He J, Li J, Ye C, et al: Cell cycle suspension: a novel process lurking in $\mathrm{G}_{2}$ arrest. Cell Cycle 10: 1468-1476, 2011.

29. Calin GA, Sevignani C, Dumitru CD, et al: Human microRNA genes are frequently located at fragile sites and genomic regions involved in cancers. Proc Natl Acad Sci USA 101: 2999-3004, 2004

30. Simone NL, Soule BP, Ly D, et al: Ionizing radiation-induced oxidative stress alters miRNA expression. PLoS One 4: e6377, 2009.

31. Kraemer A, Anastasov N, Angermeier M, Winkler K, Atkinson MJ and Moertl S: MicroRNA-mediated processes are essential for the cellular radiation response. Radiat Res 176: 575-586, 2011.

32. Chaudhry MA,SachdevaH and Omaruddin RA:Radiation-induced micro-RNA modulation in glioblastoma cells differing in DNA-repair pathways. DNA Cell Biol 29: 553-561, 2010.
33. Kwon JE, Kim BY, Kwak SY, Bae IH and Han YH: Ionizing radiation-inducible microRNA miR-193a-3p induces apoptosis by directly targeting Mcl-1. Apoptosis 18: 896-909, 2013.

34. Zhao L, Lu X and Cao Y: MicroRNA and signal transduction pathways in tumor radiation response. Cell Signal 25: 1625-1634, 2013.

35. Lal A, Pan Y, Navarro F, et al: miR-24-mediated downregulation of H2AX suppresses DNA repair in terminally differentiated blood cells. Nat Struct Mol Biol 16: 492-498, 2009.

36. Hu H, Du L, Nagabayashi G, Seeger RC and Gatti RA: ATM is downregulated by N-Myc-regulated microRNA-421. Proc Natl Acad Sci USA 107: 1506-1511, 2010.

37. Yan D, Ng WL, Zhang X, et al: Targeting DNA-PKcs and ATM with miR-101 sensitizes tumors to radiation. PLoS One 5: e11397, 2010.

38. Wang J, He J, Su F, et al: Repression of ATR pathway by miR-185 enhances radiation-induced apoptosis and proliferation inhibition. Cell Death Dis 4: e699, 2013.

39. Moskwa P, Buffa FM, Pan Y, et al: miR-182-mediated downregulation of BRCA1 impacts DNA repair and sensitivity to PARP inhibitors. Mol Cell 41: 210-220, 2011.

40. Zhang X, Wan G, Berger FG, He X and Lu X: The ATM kinase induces microRNA biogenesis in the DNA damage response. Mol Cell 41: 371-383, 2011.

41. Kawai S and Amano A: BRCA1 regulates microRNA biogenesis via the DROSHA microprocessor complex. J Cell Biol 197: 201-208, 2012

42. Zhang C-Z, Lei H, Zhang A-L, et al: MicroRNA-221 and microRNA-222 regulate gastric carcinoma cell proliferation and radioresistance by targeting PTEN. BMC Cancer 10: 367, 2010.

43. Landgraf $P$, Rusu M, Sheridan R, et al: A mammalian microRNA expression atlas based on small RNA library sequencing. Cell 129: 1401-1414, 2007.

44. Betel D, Wilson M, Gabow A, Marks DS and Sander C: The microRNA.org resource: targets and expression. Nucleic Acids Res 36: D149-D153, 2008

45. Kumar S, Kumar A, Shah PP, Rai SN, Panguluri SK and Kakar SS: MicroRNA signature of cisplatin resistant vs. cisplatin sensitive ovarian cancer cell lines. J Ovarian Res 4: 17, 2011.

46. Nordentoft I, Birkenkamp-Demtroder K, Agerbaek M, et al: miRNAs associated with chemo-sensitivity in cell lines and in advanced bladder cancer. BMC Med Genomics 5: 40, 2012. 